\title{
Personality Traits, Usage Patterns and Information Disclosure in Online Communities
}

\author{
Johann Schrammel* \\ Christina Köffel* \\ Manfred Tscheligił \\ ${ }^{*}$ CURE - Center for Usability Research and Engineering \\ Hauffgasse 3-5 \\ ${ }^{\ddagger} I C T \& S$ Center, University of Salzburg \\ Sigmund-Haffner-Gasse 18 \\ 1110 Vienna, Austria \\ 5020 Salzburg, Austria
}

\{schrammel, koeffel, tscheligi\}@cure.at

\begin{abstract}
Online communities of different types have become an important part of the daily internet life of many people within the last couple of years. Both research and business have shown interest in studying the possibilities and risks related to these relatively new phenomena. Frequently discussed aspects that are tightly bound to online communities are their implications and effects on privacy issues. Available literature has shown that users generally disclose very much (private) information on such communities, and different factors influencing this behaviour were identified and studied. However, the influence and predictive power of personality traits on information disclosure in online communities has not yet been the subject of analysis. In this paper we report the results of an online survey investigating the relations between personality traits (based on the Fife-Factor Model), usage patterns and information disclosure of participants in different types of online communities.
\end{abstract}

\section{Categories and Subject Descriptors}

H.1.2 [User/Machine Systems]: Human Factors

\section{General Terms}

Design, Security, Human Factors

\section{Keywords}

Online Communities, Social Networking Sites, Privacy, FifeFactor Model of Personality, Information Disclosure

\section{INTRODUCTION}

With the emergence of the so-called Web 2.0 phenomenon, online communities have also become an important aspect of modern (internet) life. Within the last few years they have gained an incredibly large audience. Research has indicated that 59 percent of young adults [34] and 87 percent of students [18] are members and regular users of social networking sites.

The currently largest online communities are YouTube, MySpace and Facebook with YouTube being ranked as number 3 of the most popular websites ${ }^{1}$. But not only social networks

(C) The Author 2009.

Published by the British Computer Society and content and media sharing networks are thriving, also business networking sites such as LinkedIn and Xing are steadily increasing their number of members. This trend also applies to online gaming communities and social news/bookmarking sites.

Overall it can be stated that the number of online community members is steadily increasing and so are the discussions about privacy and data disclosure issues which are frequently also treated by national and international media. Furthermore also employers started to use social networks in order to investigate future employees [13] and social engineering [21] and phishing attacks [23] have also become real risks.

These phenomena are tightly connected to the nature of online communities. A membership in a community usually requires to disclose a certain amount of information already when signing up for an account. The amount of information disclosed depends on the type of network, nevertheless almost every online community provides benefits to users that are willing to provide more data about themselves [17], [9]. Such incentives range from better recommendation systems to more information about profile visitors for paying members.

When enquired about possible risks of online communities, the majority of users indicate to be aware of possible risks of data disclosure and to care about their privacy, in reality they often act contradictory [11].

Previous research [5] has indicated that users disclose private and even sensitive data rather freely. This finding is underlined by several studies that lead to the conclusion that most users have difficulties estimating risks and consequences when dealing with private data disclosure [1], [29].

Different factors influencing the users' information disclosure behaviour have been studied [44], [31], [45]. However, we are not aware of research analysing the influence of personality traits on information disclosure in online communities.

In particular we want to investigate the relations between the users' personality traits and their usage patterns and information disclosure behaviour on online communities. It is for example, not clear whether certain information disclosure behaviours can be linked to certain personalities or if extrovert users for example tend to have more friends and are longer online than other personality types.

\section{RELATED WORK}

\subsection{Information Disclosure}

Online communities in general and social networks in particular have gained increased attention by the scientific community recently. The possible risks of information disclosure and the information disclosure behaviour on several social networks has 
been investigated by many researchers [16], [29], [30], [33], [44].

The first large-scale examination of online communities was conducted by Mislove et al. [40] who investigated a total of 11.3 million accounts from YouTube, LiveJournal, Orkut and Flickr through crawling publicly available information. They found that there is a positive correlation between the number of friends of an user in a network and how much s/he is trusted by others. Also, the social contacts are related to the information disclosure behaviour. The more information a user discloses, the more likely s/he is to have many friends [43]

Facebook is the social networking site that has been addressed extensively by different researchers, therefore detailed information about their users' information disclosure behaviour is available. On Facebook more than 60 percent of all profile pictures were suitable for identification [16]. Another 15 to 21 percent of the users could be identified in real-life because of their profile pictures and even more than 77 percent provided enough information to possibly become victims of online stalking (e.g. by posting e-mail addresses or instant messaging contacts on networks without any restriction).

Another study on context-aware spam on Facebook with 7000 profiles has shown that according to their profiles, 85 percent of users would be vulnerable to attacks [7]. Further, only 19 percent out of more than 30,000 users restricted the access to their Facebook profile according to the results gathered in [31]. This is possible through non-restrictive privacy policies and profile-information that links the users to their e-mail address in another database. Nevertheless also users with a more restrictive privacy profile are vulnerable to attacks [7]. Comparisons of different social networks have shown that for example 93.8 percent of users disclose their gender, 92.8 their e-mail address and 83.8 percent their birthday [16], [33]. Furthermore results have shown that 55 to 90 percent of users (depending on the network membership) allow their profile information to be viewable by the entire network [28]. These information disclosure behaviours are underlined by a study conducted by Tidwell and Walther who discovered that online interaction in general provoked more self-disclosure [45].

Our previous work in this area was connected to information disclosure depending on the type of community [5]. The obtained results have indicated that especially users of social networks and business networks disclose more information than users of other types of communities such as gaming, content sharing or social news networks. Additionally, students and pupils provide more information on social and business networking communities.

Further research by [16] has indicated that users who are more freely disclosing information are more likely to have a higher number of friends. According to [40] this would make those users appear to be more trustworthy.

\subsection{Trust and Privacy}

Online networks do offer pre-defined privacy settings to their users. These settings provide detailed possibilities to restrict certain information to chosen user groups such as friends or self-defined groups. Nevertheless most users have the opinion that "an honest man has nothing to fear" [9] and therefore tend to not change these settings [30]. In fact, an overall of 79 percent of users does not change the provided default settings and are satisfied with their privacy level [37]. This tendency is even more distinctive for Twitter, where 99 percent of the users preferred to keep their default settings and on Facebook where only 1.2 percent of users changed the default privacy settings [16]. Furthermore the default settings offered by the networks are a point of frequent discussion and are even perceived to be too restrictive for contact-seeking users [25]. Ahern et al [2] for example investigated the affects of location disclosure and the management of privacy settings in the online photo-sharing network Flickr. Their findings indicate that privacy decisions are often correlated with the context of capture and the content of the photo.

The privacy-friendliness of the providers of online community sites is also the target of research. [12] studied common social and business networks and discovered that none of the tested platforms is entirely safe to use. In their results, Facebook and LinkedIn were ranked as the best social and professional networks respectively. Also according to Lucas and Borisov [35], one of the largest privacy risks for users of social networking sites is the service provider's possibility to observe and save the information that they transmit over the network. Guha et al. [17] even state that recently users are trading their online-privacy for services. They argue that it would be possible for providers to warranty full privacy to the users, but this would conflict with their interests of making money with the acquired data (e.g. marketing information). According to Mannan and Oorschot [37] the privacy-problem is also caused by a misunderstanding of the implications of data disclosure and Korolova et al. [27] link privacy issues to the lookahead (i.e. the number of one's friends that can be seen) provided.

A long-term investigation of Facebook has noticed a change in privacy behaviour over time - users got more privacy aware over the duration of the survey (meaning that they have changed their privacy settings). Nevertheless the way of using Facebook has not significantly changed over time [32]. Research indicates that users do not entirely trust online communities [4] and that trust is also dependent on whether or not one knows the contacts also offline [6]. Another important factor that has considerable impact onto the user's perception of trust is the (often negative) publicity in connection with online communities [19], [26].

To counter the privacy and trust issues in connection with online communities, different considerations have already been made. These either target the increase of the user's trust [4],[24], the recovering from breakdowns [42],[46] or the protection of the user's information from the provider side [17],[35],[37]. Furthermore design implications for online communities targeting the aspects of privacy are available [30] and even security recommendations for social networks are made [20]. Nevertheless Preibush et al. claim the area of privacy in social networks to be severely under-researched [41].

\subsection{Online Behaviour and Personality}

\section{Factors}

One of the most used and stable models in personality research is the fife-factor model. This model consists of five dimensional traits: Neurotisism, extraversion, openness to experience, agreeableness and conscientiousness. A detailed analysis and description of the model and the characteristics of the different traits can be found in [38].

These five personality traits have been used to research online behaviour. For example, individuals scoring high on neuroticism for example were found to be likely to use the Internet to avoid loneliness [8]. Similarly [47] found a high interest of using the internet for communication for those with high levels on neuroticism. [3] describe that introverted 
individuals (i.e. low score on the trait of extraversion) are more likely to use computer mediated communication means for their communication needs. Butt and Phillips [8] report that conscientiousness is negatively related to the use of internet.

Researching Facebook Ross et al. [43] found that personality factors do not appear to be as influential as described in previous literature such as [41], [28]. Nevertheless they found that extraverts reported significantly more memberships in groups, however they could not find the expected relation of extraversion to number of friends or online time.

The influence of personality types onto a user's trust perception towards a website has been investigated by Lumsden and MacKay [36], who have also discussed whether a user's personality type influences their attitude towards trust assessment. Their investigations did not lead to any statistically significant conclusions, indicating that a user's personality type does not affect his/her trust level towards a website. Nevertheless they were able to discover some connections between trust and e-commerce. For example, they discovered that extroverts are more disposed to trust.

\section{RESEARCH QUESTIONS}

The previous review of related work shows that valuable research and data is available for online information disclosure behaviour on different communities as well as for personality patterns in connection to the use of online services. However, there are several aspects connected to the aforementioned factors that have not been addressed sufficiently yet.

Our main research questions target the influence of personality traits on the usage patterns of online communities as well as the amount of information disclosed in different online communities both to friends and to the whole community. In detail our research hypotheses were:

a) Related to usage patterns:

- Individuals scoring high on the trait of extraversion have a greater tendency to be sociable; therefore we expected them to have more friends and spend more time on online networks.

- Because individuals that score high on the trait of agreeableness tend to engage in mature relationships we expected them to have more friends related to their profiles in online networking sites.

- Due to their tendency to be curious and desire to explore new activities, individuals who scored higher on the trait of openness to experience were expected to have joined online networks earlier, to spend more time in online networks, and to have more friends in the network.

- Due to the typically strong interest of individuals with high scores on the trait of neurotisism in using the internet for communication [47] we expected them to spend more time in online networks than individuals with a lower score.

b) Related to information disclosure:

- Individuals who score high on extraversion were expected to disclose more information as they tend to be more outgoing.

- Individuals who score higher on the trait of openness to experience where expected to provide more information as the provision of information frequently is a prerequisite to make new experiences.
- We expected individuals that score high on the trait of agreeableness - which reflects the tendency to be trusting, sympathetic and cooperative - to provide more information in their profiles.

- As a high score on the trait of neuroticism is associated with sensitivity to threat we expected individuals to provide less information online, as this is potentially harmful.

\section{PROCEDURE}

We developed an online questionnaire to obtain insights into users' motivations for their behaviour and in order to investigate connections between personalities and behaviour patterns. This questionnaire included the Five Factor Personality scale which is based on the IPIP Scales from Goldberg et al. [14],[14] and is available on the International Personality Item Pool [22]. The Five Factor model we employed consisted of five positive and five negative keyed factors for each trait.

With regard to information disclosure a set of 10 items typically available at different types of online communities was identified $^{2}$. In the questionnaire users where asked for each type of community they where using whether they provide this information at all or both to the entire network or to friends only. A simple index for information disclosure was calculated by counting the number of items visible to friends respectively all users.

For recognizing behavioural patterns within different communities we also included community-specific questions, such as the time since when they are using communities. Furthermore the users were asked questions on their motivations for joining online communities, which community they joined first and where they got the information about the community from (e.g. internet sources, friend recommendation, etc.).

Users who have previously participated on a survey about information disclosure behaviour, experiences and usage patterns concerning different online community types [5], were contacted again to take part in a second survey. For this first study participants had been recruited by different channels. First, all participants of our test user database, where people interested in participating in usability tests can sign up (which specified they use the internet intensely), were invited by mail. Additionally several universities were contacted and asked for permission to distribute the questionnaire within their institutions.

As an incentive users were given the possibility to participate in a raffle for prices. Amazon.com gift vouchers were chosen as the main incentive, altogether 50 gift vouchers with a value of 10 Euros, 5 vouchers with a value of 30 Euro and one voucher with a value for 50 Euro were raffled.

The survey was created using LimeSurvey software and made available on our website between December 15, 2008 and January 15, 2009.

\footnotetext{
${ }^{2}$ In detail these items were real name, nickname, date of birth, picture of user, email-address, physical address, phone number, instant messaging contact, network of friends, link to website of user.
} 


\section{PARTICIPANTS}

In total we received 162 completed questionnaires. The questionnaire's respondents came from several countries, with a vast majority of participants living in German speaking countries (Austria: 154, Germany: 6). Our previous study was completed by 856 participants, of whom 736 provided contact information. Hence, we could acquire a response rate of 22 percent (i.e. 162 completed questionnaires).

The distribution of participants with regard to their sex was almost equal with a slight majority of female users (53.7 percent female versus 46.3 percent male). Compared to our last survey, where more male participants were acquired, this indicates, that females appear to be more willing to volunteer for repeated studies.

The age distribution of the participants can be found in Table 1 below. A predominant majority of users was in the age group of 21 to 30 years. This probably is caused by three effects: Firstly, this age group is most active in online communities. The popularity of Facebook and similar networks in universities is a good indicator for this. Secondly, students were directly recruited for the questionnaire through contacts to different universities. Thirdly, young people in education are typically easier to be motivated by a small amount of money than older people with an income.

Table 1: Age Distribution of Study Participants

$\begin{array}{lccccccc}\text { Age group } & <15 & 15-20 & 21-30 & 31-40 & 41-50 & 51-60 & 60+ \\ \text { Frequency } & 0 & 11 & 102 & 27 & 9 & 10 & 3 \\ \text { Percent } & 0 & 6.8 & 63.0 & 16.7 & 5.5 & 6.2 & 1.9\end{array}$

In compliance with the results regarding age as described above, the dominating professions of the questionnaire participants were either student or pupil (47.5 percent, 77 persons) or employees (40.7 percent, 66 persons).

About 44 percent of the questionnaire participants have a university or college degree and 42.6 percent have finished the school leaving examination. Only few participants with compulsory or apprentice level education participated in our survey (13 percent).

Altogether the majority of participants considered themselves to be rather advanced computer users. Out of 162 respondents 89 (54.9 percent) indicated that they rarely need help when working with computers and 37 (22.8 percent) stated that they never need help. Only 1.9 percent stated that they often need help and 20.4 percent said that they sometimes need support when using computers.

Concerning the time spent online, a slight majority of participants ( 34 percent) actively uses the internet between 5 and 15 hours a week. Between 16 and 30 hours of internet use a week can be accounted to 32.7 percent of participants. Only 3.7 percent use the internet less than one hour and 6.2 percent are online even more than 50 hours a week. Summarising it can be stated that over 90 percent of users spend between 5 and 50 hours a week online.

\section{RESULTS}

A known methodological challenge of personality research is that of the typically small effect sizes. In order to increase the sensitivity of the statistical methods applied we followed an approach similar to that applied by Ross et al. [43]. Personality dimensions were divided into thirds in terms of percentiles, and individuals that scored in the upper third where compared to individuals falling into the lowermost third. This procedure ensured both increased sensitivity of the applied statistical methods and good comparability of results.

Usage Patterns. Consistent with our expectations, individuals in the high extraversion group reported a higher number of friends (Mean=60,08) than individuals in the low extraversion group (Mean=41,03), $\mathrm{t}_{75}=-1.776, \mathrm{p}=0.040$. [43] also expected such a relation in their study, but in contrast to us they could not find a significant relationship. This may be related to several differences in the setup. First, they used a smaller sample and therefore an existing (small) effect might have not been detected. Second, the differences in results might be related to the different populations. Whereas our sample consisted predominantly of European users Ross sample was Canadian. Also there are important differences in gender distribution and occupational background.

In contrast to our expectation - but consistent with Ross et al. [43] - time spend on the community was not significantly related to extraversion $\left(\mathrm{t}_{75}=-1.332, \mathrm{p}=0.094\right)$. We think this might be explained by the increased tendency of introverts to use computer mediated communication means for their communication [3] which counteracts potential differences between individuals scoring on opposite ends of the extraversion scale.

Contrary to our hypothesis agreeableness is not related to the number of friends in online communities $\left(\mathrm{t}_{75}=0.792, \mathrm{p}=0.223\right)$. Individuals that can be characterized

Openness to experience did show the two expected relations to number of friends $\left(\mathrm{t}_{74}=-1,988, \mathrm{p}=0.025\right)$ and time spend online $\left(t_{74}=-2.307, p=0.012\right)$. Put in other words, people who are rather curious and open for new experiences tend to spend more time in online networks and have more friends added to their profile. However, contrary to our hypothesis, there was no significant relation of openness to the amount of time since the first usage of online communities. Our data do not support the notion that people scoring high on openness to experience did start to use online communities earlier.

Information disclosure. In contrast to the previous section where we could identify several significant and expected relations between personality traits and usage patterns there were no significant findings for any of the hypotheses related to information disclosure. Personality traits do not seem to have any predictive power on the disclosure of information in online communities.

This result is very surprising to us, as we expected a clear influence of several personality traits on the amount of information that is provided. However, or data do not support this expectation.

Correlation of usage patterns and information disclosure. Online time does significantly correlate with both, the information disclosure to unknown persons $(r=0.191, p=0.017)$ and friends $(\mathrm{r}=0.174, \mathrm{p}=0.027)$ in online communities. As expected, people who spend more time on online communities provide more information in their profile. These results are in line with similar research reported in [31].

The number of friends in online communities shows a positive correlation with the information disclosure to known persons $(r=0.176, p=0.264)$. There is no significant correlation to the information disclosure to unknown persons.

Also the self-reported trust of users in the online communities correlates significantly with the provision of information to friends $(r=0.29, p=0.001)$ and the whole community $(r=0.47$, 
$\mathrm{p}<0.0005)$. The higher $\mathrm{r}$-value for the whole community illustrate that trust is more important when dealing with unknown persons than when interacting with friends.

\section{DISCUSSION \& CONCLUSION}

The main goal of this study was to examine the relationship of personality factors with usage patterns and information disclosure behaviour in online communities

With regard to the relationship of personality traits and usage patterns our work provided clear and mostly expected results that help to better understand the influence of personality traits on online behaviour and extend and confirm existing knowledge on this topic to the context of online communities.

The most surprising result however was that we couldn't find any significant relations between personality traits and information disclosure. We think these results might be related to another factor that was not covered in our questionnaire and that might influence the information disclosure behaviour much stronger than personality factors and therefore mask possible effects. We have the hypothesis that the actual usage purpose and goal of a user when interacting with a community is the main driving factor behind the information disclosure behaviour. For example a community member whose main goal is to initiate a romantic relationship might provide very different types and amounts of information compared to a user interested in exploring new trends or in keeping in touch with old friends.

A second possible explanation for this lack of significant results might be that information disclosure is mainly related to factors that are rather independent from the five factor approach to personality.

Future work should explicitly include different goals and motivations of users to clarify this issue.

\section{ACKNOWLEDGMENTS}

The research leading to these results has received funding from the European Community's Seventh Framework Programme (FP7/2007-201, grant agreement $n^{\circ} 215056$ ).

\section{REFERENCES}

[1] Acquisti, A., and Gross, R. 2006. Imagined Communities: Awareness, Information Sharing, and Privacy on the Facebook, in Post-Proc. 6th International Workshop on Privacy Enhancing Technologies (PET 2006), 36-58.

[2] Ahern, S., Eckles, D., Good, N. S., King, S., Naaman, M., and Nair, R. 2007. Over-exposed?: privacy patterns and considerations in online and mobile photo sharing. In Proc.CHI '07, 357-366.

[3] Amichai-Hamburger, Y., Wainpel, G., and Fox, S. 2002. On the Internet no one knows I'm an introvert: Extroversion, introversion, and Internet interaction. CyberPsychology \& Behavior, 5(2), 125-128.

[4] Andrews, D. C. 2002. Audience-specific online community design. Commun. ACM 45, 4 (Apr. 2002), 6468.

[5] Schrammel, J., Köffel, C., and Tscheligi, M. 2009. How Much do You Tell? Information Disclosure Behaviour in Different Types of Online Communities. In Proc. $4^{\text {th }}$ International Conference on Communities and Technologies.
[6] boyd, d. m. 2003. Reflections on Friendster, Trust and Intimacy. Ubiquitous Computing (Ubicomp 2003), Workshop app. for the Intimate Ubiquitous Computing.

[7] Brown, G., Howe, T., Ihbe, M., Prakash, A., and Borders, K. 2008. Social networks and context-aware spam. In Proc. ACM 2008 Conference on Computer Supported Cooperative Work. CSCW '08, 403-412.

[8] Butt, S., and Phillips, J. G. 2008. Personality and self reported mobile phone use. Computers in Human Behavior, 24(2), 346-360

[9] Conti, G., and Sobiesk, E. 2007. An honest man has nothing to fear: user perceptions on web-based information disclosure. In Proc. SOUPS '07, vol. 229, 112-121.

[10] Ellison, N. B., Lampe, C., and Steinfield, C. 2009. Social network sites and society: current trends and future possibilities. Interactions 16, 1 (Jan. 2009), 6-9.

[11] Flinn, S., and Lumsden, J. 2005. User Perceptions of Privacy and Security on the Web. In The Third Annual Conference on Privacy, Security and Trust (PST 2005).

[12] Fraunhofer Institut für Sichere Informationstechnologie Privatsphärenschutz in Soziale-Netzwerke-Plattformen. http://www.sit.fraunhofer.de/fhg/Images/SocNetStudie_De u_Final_tcm105-132111.pdf. Last access: 2008-12-15.

[13] Fuller, A. Employers snoop on Facebook, The Stanford Daily, http://daily.stanford.edu/article/2006/1/20/ employersSnoopOnFacebook. Last access: 2009-03-04.

[14] Goldberg, L. R. 1999. A broad-bandwidth, public domain, personality inventory measuring the lower-level facets of several five-factor models. In I. Mervielde, I. Deary, F. De Fruyt, \& F. Ostendorf (Eds.), Personality Psychology in Europe, Vol. 7 (pp. 7-28). Tilburg University Press.

[15] Goldberg, L. R., Johnson, J. A., Eber, H. W., Hogan, R., Ashton, M. C., Cloninger, C. R., and Gough, H. C. 2006. The International Personality Item Pool and the future of public-domain personality measures. Journal of Research in Personality, 40, 84-96.

[16] Gross, R., Acquisti, A., and Heinz, H. J. 2005. Information revelation and privacy in online social networks. In Proc. 2005 ACM Workshop on Privacy in the Electronic Society. WPES '05, 71-80.

[17] Guha, S., Tang, K., and Francis, P. 2008. NOYB: privacy in online social networks. In Proc. First Workshop on online Social Networks. WOSP '08, 49-54.

[18] Hargittai, E. 2007. Whose Space? Differences Among Users and Non-Users of Social Network Sites. Journal of Computer-Mediated Communication, 13(1).

[19] Hart, J., Ridley, C., Taher, F., Sas, C., and Dix, A. 2008. Exploring the Facebook experience: a new approach to usability. In Proc. 5th Nordic Conference on HumanComputer interaction: Building Bridges. NordiCHI '08, vol. 358, 471-474.

[20] Hogben, G. H. (Editor). 2007. Security Issues and Recommendations for Online Social Networks. ENISA Position Paper No. 1. October 2007.

[21] Hui, K., Tan, B. C., and Goh, C. 2006. Online information disclosure: Motivators and measurements. ACM Trans. Interet Technol. 6, 4 (Nov. 2006), 415-441.

[22] International Personality Item Pool: A Scientific Collaboratory for the Development of Advanced Measures 
of Personality Traits and Other Individual Differences (http://ipip.ori.org/). Last access: 2009-03-04.

[23] Jagatic, T. N., Johnson, N. A., Jakobsson, M., and Menczer, F. 2007. Social phishing. Commun. ACM 50, 10 (Oct. 2007), 94-100.

[24] Jensen, C., Davis, J., and Farnham, S. 2002. Finding others online: Reputation systems for social online spaces. Proc. CHI2002, 447-454.

[25] Joinson, A. N. 2008. 'Looking at', 'Looking up' or 'Keeping up with' People? Motives and Uses of Facebook. In Proc. CHI 2008.

[26] Jones, H., and Soltren, J. H. 2005. Facebook: Threats to Privacy. MIT Whitepaper, December 14, 2005.

[27] Korolova, A., Motwani, R., Nabar, S. U., and Xu, Y. 2008. Link privacy in social networks. In Proc. CIKM '08.

[28] Kraut, R., Kiesler, S., Boneva, B., Cummings, J., Helgeson, V., and Crawford, A. 2002. Internet paradox revisited. Journal of Social Issues, 58(1), 49-74.

[29] Krishnamurthy, B., and Wills, C. E. 2008. Characterizing privacy in online social networks. In Proc. First Workshop on online Social Networks WOSP '08, 37-42.

[30] Krishnamurthy, B., Gill, P., and Arlitt, M. 2008. A few chirps about twitter. In Proc. First Workshop on online Social Networks. WOSP '08, 19-24.

[31] Lampe, C. A., Ellison, N., and Steinfield, C. 2007. A familiar face(book): profile elements as signals in an online social network. In Proc. CHI 2007, 435-444.

[32] Lampe, C., Ellison, N. B., and Steinfield, C. 2008. Changes in use and perception of Facebook. In Proc. ACM 2008 Conference on Computer Supported Cooperative Work. CSCW '08, 721-730.

[33] Lampe, C., Ellison, N., and Steinfield, C. 2006. A face(book) in the crowd: social Searching vs. social browsing. In Proc. 2006 20th Anniversary Conference on Computer Supported Cooperative Work. CSCW '06, 167170.

[34] Li, C. 2007. How Consumers Use Social Networks. Forrester Research. June 21, 2007.

[35] Lucas, M. M., and Borisov, N. 2008. FlyByNight: mitigating the privacy risks of social networking. In Proc. 7th Work-shop on Privacy in the Electronic Society. WPES '08, 1-8.
[36] Lumsden, J., and MacKay, L. 2006. How does personality affect trust in $\mathrm{B} 2 \mathrm{C}$ e-commerce?. In Proc. 8th international Conference on Electronic Commerce. ICEC '06, 471-481.

[37] Mannan, M., and van Oorschot, P.C. 2008. Privacyenhanced sharing of personal content on the web. In Proc. 17th international Conference on World Wide Web. WWW '08, 487-496.

[38] McCrae, R. R. (1992). The five-factor model: Issues and applications [Special issue]. Journal of Personality, 60(2).

[39] Mckenna, K., Green, A., and Gleason, M. 2002. Relationship formation on the internet: What's the big attraction? Journal of Social Issues, vol. 58, no. 1, pp. 931.

[40] Mislove, A., Marcon, M., Gummadi, K. P., Druschel, P., and Bhattacharjee, B. 2007. Measurement and analysis of online social networks. In Proc. 7th ACM SIGCOMM Conference on internet Measurement. IMC '07, 29-42.

[41] Phillips, J.G., Butt, S., and Blaszczynski, A. 2006. CyberPsychology \& Behavior. 9(6): 753-758.

[42] Riegelsberger, J., and Vasalou, A. 2007. Trust 2.1: advancing the trust debate. In Extended Abstracts CHI '07, 2137-2140.

[43] Ross, C., Orr, E. S., Sisic, M., Arseneault, J. M., Simmering, M. G., and Orr, R. R. 2009. Personality and motivations associated with Facebook use. Comput. Hum. Behav. 25, 2 578-586.

[44] Stutzman, F. 2006. An Evaluation of Identity-Sharing Behavior in Social Network Communities. International Digital and Media Arts Journal, 3(1).

[45] Tidwell, L. C., and Walther, J. B. 2002. Computermediated communication effects on disclosure, impressions, and interpersonal evaluations: Getting to know one another a bit at a time. Human Communication Research, 28(3), 317-348.

[46] Vasalou, A., and Riegelsberger, J. 2008. Recovering Trust and Avoiding Escalation: An overlooked design goal of social systems. In Proceedings of CHI 2008.

[47] Wolfradt, U., and Doll, J. (2001). Motives of adolescents to use the Internet as a function of personality traits, personal and social factors. Journal of Educational Computing Research, 24(1), 13-27. 